\title{
Extracorporeal membrane oxygenation for graft failure after heart transplantation: Recent Vienna experience
}

\author{
S. Taghavi, MD, ${ }^{a}$ H. J. Ankersmit, MD, a G. Wieselthaler, MD, ${ }^{a}$ M. Gorlitzer, MD, ${ }^{a}$ A. Rajek, MD, ${ }^{b}$ E. Wolner, MD, ${ }^{a}$

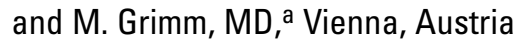

$\mathrm{P}$ rimary graft failure in recipients of cardiac allografts is a life-threatening condition that demands implantation of an extracorporeal membrane oxygenator (ECMO) to wean these patients from cardiopulmonary bypass (CPB). In this report, we are presenting our recent experience with 6 patients who underwent ECMO insertion after primary allograft failure. We were able to wean 5 patients from ECMO. One patient died on ECMO support after retransplantation. Two other patients died of sepsisinduced multiple organ failure after successful weaning. This series suggests that ECMO implantation is feasible in overcoming primary organ failure.

No consensus has been reached on the indications for mechanical support after heart transplantation in adults having intraoperative graft failure. The literature on extracorporeal life support and primary graft failure is scarce, and information and guidelines pertaining to this life-threatening condition are limited. ${ }^{1,2}$ Right and left ventricular assist devices have been of moderate benefit in this critical clinical setting. ${ }^{3}$ ECMO support is used in patients with postcardiotomy shock syndrome ${ }^{4}$ or acute respiratory distress syndrome. ${ }^{5}$ ECMO is currently used in our institution to avoid reperfusion edema after lung transplantation and in patients with primary pulmonary hypertension. In this article, we are describing our recent experience in patients with primary allograft failure treated by implantation of an ECMO.

\section{Methods and Results}

ECMO characteristics and technique and outcome. The ECMO adult circuit consisted of a Medtronic console 450 or 550 and a Medtronic Bio-Cal Blood Temperature Control Module (Medtronic, Inc, Minneapolis, Minn). The oxygenator is a hollowfiber membrane oxygenator with an integrated heat exchanger. The cannulas are Medtronic Bio-Medicus (Eden Prairie, Minn) cannulas that are wirewound to prevent kinking and are radiopaque. The setup of the ECMO involved cutdown cannulation of the femoral

From the Departments of Cardio-Thoracic Surgery a and Anesthesiology, ${ }^{\mathrm{b}}$ General Hospital Vienna, Vienna, Austria.

Received for publication Feb 14, 2001; accepted for publication March 8, 2001.

Address for reprints: S. Taghavi, MD, General Hospital Vienna, Department of CT Surgery, Währinger Gürtel 18-20, 1090 Vienna, Austria (E-mail: taghavis@hotmail.com).

J Thorac Cardiovasc Surg 2001;122:819-20

Copyright $(\odot 2001$ by The American Association for Thoracic Surgery

$0022-5223 / 2001 \$ 35.00+0 \quad \mathbf{1 2 / 5 4 / 1 1 5 6 9 2}$

doi:10.1067/mtc.2001.115692 vein and artery. Drainage was accomplished from the right atrium via the femoral vein, whereas the oxygenated blood was reinfused through the femoral artery. The distal femoral artery was perfused through the additional cannula.

Acute graft failure developed in 6 adult patients after orthotopic heart transplantation. These patients underwent extracorporeal life support (ECMO, Medtronic) to be weaned from CPB (Table 1) The charts of this patient cohort were reviewed. Three patients had dilatative cardiomyopathy, 2 patients had ischemic cardiomyopathy, and 1 patient had malignant recurrent ventricular arrhythmia (male/female ratio 5:1, mean age $46 \pm 17$ years, range 28-60 years). Four patients were supported with ECMO for intraoperative biventricular failure, and 2 recipients had right ventricular dysfunction caused by pulmonary hypertension refractory to alprostadil (prostaglandin $\mathrm{E}_{1}$ )/nitric oxide therapy. The hemodynamic data, donor age, and total ischemic time are listed in Table 2.

\section{Comment}

The prognosis of patients with end-stage cardiomyopathy is poor, and heart allograft transplantation is the standard modality with documented long-term results. ${ }^{6}$ Allograft malfunction with subsequent nonweaning from $\mathrm{CPB}$ can be a result of a multifactorial genesis, including effects of ischemia, preservation injury, denervation, acute humoral and cellular rejection, and surgical manipulation. Additionally, extracorporeal circulation is associated with a release of vasoactive substances. ${ }^{7,8}$ Increased vascular resistance is associated with a life-threatening risk of right ventricular failure after heart transplantation and is a widely established predictor of mortality in heart transplantation. ${ }^{9}$ This in turn results in an acute increase in right ventricular afterload for the allograft and may lead to right ventricular failure; left ventricular failure is deemed to be caused by preservation injury. As a result of these conditions, the patient cannot be weaned from $\mathrm{CPB}$ with conservative therapy. Inotropic drugs are given to increase ventricular contractility and heart rate. More important, a reduction of pulmonary vascular resistance may improve ventricular performance and prevent right ventricular failure after heart transplantation. Alprostadil (prostaglandin $\mathrm{E}_{1}$ ) and nitric oxide have been shown to be potent but nonselective pulmonary vasodilators with the potential for reduced pulmonary afterload. However, despite maximal drug treatment, some allograft recipients may require mechanical support to be weaned from CPB because of severe myocardial injury and pulmonary hypertension. Since installation of right or left ventricular assist devices is a viable option in this scenario, the cost effectiveness and more invasiveness of this procedure may limit applicability. In our institution, after reaching threshold levels of inotropic drug use (norepinephrine $0.2 \gamma$, suprarenin $0.3 \gamma$ [1 $\left.\gamma=\mu \mathrm{g} \cdot \mathrm{kg}^{-1} \cdot \mathrm{min}^{-1}\right]$ ), we are opting for insertion of ECMOs via venoarterial access because this is a less invasive procedure. 
TABLE 1. Six patients with acute graft failure after orthotopic heart transplantation who required ECMO to be weaned from CPB

\begin{tabular}{lccccc}
\hline Patient (sex, age [y]) & Diagnosis & Indications for ECMO & Duration of ECMO (h) & Weaning & Survival \\
\hline $1(\mathrm{M}, 60)$ & ICMP & Biventricular failure & $49 \mathrm{~h}(\mathrm{RHTX})$ & No & No \\
$2(\mathrm{~F}, 47)$ & HCMP & RVF & $94 \mathrm{~h}$ & Yes & No, POD 18, urosepsis \\
$3(\mathrm{M}, 57)$ & RVF & $120 \mathrm{~h}$ & Yes & Yes \\
$4(\mathrm{M}, 57)$ & DCMP & Biventricular failure & $125 \mathrm{~h}$ & Yes & No, sepsis \\
$5(\mathrm{M}, 28)$ & ICMP & Biventricular failure & $32 \mathrm{~h}$ & Yes & Yes \\
$6(\mathrm{M}, 34)$ & DCMP & $38 \mathrm{~h}$ & Yes & Yes \\
\hline
\end{tabular}

ICMP, Ischemic cardiomyopathy; HCMP, hypertrophic cardiomyopathy; DCMP, dilatative cardiomyopathy; $R V F$, right ventricular failure; $R H T X$, retransplantation; $P O D$, postoperative day.

TABLE 2. Hemodynamic data, donor age, and total ischemic time

\begin{tabular}{lccccc}
\hline Patient & PAP(s/d/m) & PVR (WU) & LVEF (\%) & Donor age & Total ischemic time (min) \\
\hline 1 & $56 / 36 / 43$ & 5.3 & 10 & $59 \mathrm{M}$ & 207 \\
2 & & & $28 \mathrm{~F}$ & 230 \\
3 & $64 / 29 / 42$ & 3.1 & 30 & $28 \mathrm{~F}$ & 201 \\
4 & $53 / 28 / 38$ & 3.3 & 12 & $43 \mathrm{M}$ & 150 \\
5 & $56 / 32 / 40$ & 1 & 30 & $35 \mathrm{M}$ & 180 \\
6 & $36 / 18 / 25$ & 0.2 & 32 & $25 \mathrm{~F}$ & 225 \\
\end{tabular}

PAP, Pulmonary artery pressure; $s / d / m$, systolic, diastolic, mean; PVR, pulmonary vascular resistance; $W U$, Wood units; $L V E F$, left ventricular ejection fraction.

Owing to the scarcity of literature relating to this therapeutic modality in adults, various aspects deserve comment. First, patient referral from the operating theater was possible in all patients. Second, weaning from ECMO was possible in $82.3 \%$, within a mean period of $71.4 \pm 41.9$ hours. Because of the circulatory support, right and left ventricular distention was reduced and recovery of allograft heart function was made possible. Patients were weaned from ECMO in a stepwise fashion with echocardiographic and hemodynamic monitoring. Third, as a result of immunosuppressive treatment, 2 patients died of multiorgan failure after verified blood-borne sepsis. This warrants aggressive prophylactic antibiotic and antimycotic treatment. Our single-center experience suggests that ECMO is a feasible and cost-effective mechanical support to overcome primary allograft dysfunction.

\section{References}

1. Wang S-S, Chu SH. Current status of heart assist and replacement in Taiwan. Artif Organs. 1996;20:1325-9.
2. Barzaghi N, Olivei M, Minzioni G, Degani A, Barschi A, Vigano M. ECMO and inhaled nitric oxide for cardiopulmonary failure after heart retransplantation. Ann Thorac Surg. 1997;63:533-5.

3. Kanter KR, Pennington DG, McBride LR, Miller LW, Swartz MT, Naunheim KS, et al. Mechanical circulatory assistance after heart transplantation. J Heart Transplant. 1987;6:150-4.

4. Helman DN, Morales DL, Edwards NM, Mancini DM, Rose EA, Oz MC. Left ventricular assist device bridge-to-transplant network improves survival after failed cardiotomy. Ann Thorac Surg. 1999;68:1187-94.

5. Kolla S, Awad S, Rich P, Schreiner R, Hirschl R, Barlett R. Extracorporeal life support for 100 patients with severe respiratory failure. Ann Surg. 1997;226:544-66.

6. Shumway NE. Thoracic transplantation. World J Surg. 2000;24:811-4.

7. Morita K, Ihnken K, Buckberg GD, Sherman MP, Ignaro LJ. Pulmonary vasoconstriction due to impaired nitric oxide production after cardiopulmonary bypass. Ann Thorac Surg. 1966;61:1775-80.

8. Riedel B. The pathophysiology and management of perioperative pulmonary hypertension with specific emphasis on the period following cardiac surgery. Int Anesthesiol Clin. 1999;37:55-79.

9. Zuckerman AO, Ofner P, Holzinger $\mathrm{C}$, et al. Pre- and early postoperative risk factors for death after cardiac transplantation: a single center analysis. Transplant Int. 2000;13:28-34. 